\title{
ANALISIS KESESUAIAN KORIDOR HALIMUN SALAK SEBAGAI PERLUASAN HABITAT MACAN TUTUL JAWA (Panthera pardus melas) \\ DI TAMAN NASIONAL GUNUNG HALIMUN SALAK \\ (Suitability Analysis of the Halimun Salak Corridor as Habitat Extension of Javanese Leopards (Panthera pardus melas) in Gunung Halimun Salak National Park)
}

\section{Ikhwal Riza Ardiansyah ${ }^{1 *}$, Jarwadi Budi Hernowo ${ }^{1}$ dan/and Hendra Gunawan ${ }^{2}$}

${ }^{1}$ Departemen Konservasi Sumberdaya Hutan dan Ekowisata, Fakultas Kehutanan, Institut Pertanian Bogor, Kampus IPB Darmaga, 16680, Tlp./Fax: (0251) 8621947

${ }^{2}$ Pusat Penelitian dan Pengembangan Hutan, Jl. Gunung Batu No. 5 P.O. Box 165, Bogor 16610, Kota Bogor, Jawa Barat, Indonesia, Tlp. (0251) 8638111

\begin{tabular}{|c|c|}
\hline Info artikel: & ABSTRACT \\
\hline $\begin{array}{l}\text { Keywords: } \\
\text { Panthera pardus } \\
\text { melas, } \\
\text { Javan leopard, } \\
\text { habitat suitability, } \\
\text { corridor }\end{array}$ & $\begin{array}{l}\text { Javan leopards of the same sex will usually avoid each other and even fight over their } \\
\text { habitat. The corridor area of Mount Halimun Salak, which functions as a channel for } \\
\text { genetic exchange, can expand the habitat of the Javan leopard. This research aimed to } \\
\text { determine the parts of the suitable corridor area for the Javan leopard habitat (Panthera } \\
\text { pardus melas) by creating a habitat suitability map. Data were collected from camera traps } \\
\text { and field surveys. The data collected included the presence of the Javan leopard, habitat } \\
\text { conditions and habitat disturbance. The variables for habitat suitability analysis were } \\
\text { slope, altitude, land cover, prey animal, and distance from the disturbance sources. The } \\
\text { results showed that in the corridor area, four Javan leopards and } 18 \text { potential prey species } \\
\text { were observed. The habitat suitability map revealed that } 49 \% \text { of the area categorized as } \\
\text { high suitability, and } 40 \% \text { as medium suitability, indicating that most of the corridor areas } \\
\text { are still suitable as a Javan leopard habitat. However, efforts are still needed to monitor, } \\
\text { control, and guard against habitat disturbances such as illegal logging, poaching, land } \\
\text { clearing, grass hunting, and motocross activities. }\end{array}$ \\
\hline
\end{tabular}

\section{Kata kunci:}

Panthera pardus melas,

macan tutul jawa, kesesuaian habitat, koridor

Riwayat artikel: Tanggal diterima: 31 Agustus 2019; Tanggal direvisi: 04 Agutus 2020; Tanggal disetujui: 28 Agustus 2020

\begin{abstract}
ABSTRAK
Macan tutul jawa yang memiliki jenis kelamin sama biasanya akan saling menghindar bahkan bertengkar untuk memperebutkan habitatnya. Areal koridor Gunung Halimun Salak yang berfungsi sebagai saluran pertukaran genetik dapat menjadi perluasan habitat macan tutul jawa. Penelitian ini dilakukan untuk mengetahui bagian-bagian areal koridor yang sesuai sebagai habitat macan tutul jawa (Panthera pardus melas) dengan membuat peta kesesuaian habitat. Data diambil dengan pemasangan kamera jebak dan survei lapang. Data yang diambil meliputi keberadaan macan tutul jawa, kondisi habitat, dan gangguan habitat. Analisis kesesuaian habitat menggunakan variabel kelerengan, ketinggian, tutupan lahan, satwa mangsa, dan jarak dari sumber gangguan. Hasil penelitian menunjukkan pada areal koridor ditemukan sebanyak empat individu macan tutul jawa dan terdapat 18 jenis mangsa potensial. Dalam peta kesesuaian habitat, diketahui bahwa $49 \%$ memiliki kesesuaian tinggi dan $40 \%$ memiliki kesesuaian sedang. Hasil ini mengindikasikan bahwa sebagian besar areal koridor masih sesuai sebagai habitat macan tutul jawa. Namun demikian masih tetap diperlukan upaya untuk pemantauan, pengendalian dan penjagaan terhadap gangguan habitat seperti penebangan liar, perburuan liar, pembukaan lahan, pencarian rumput serta kegiatan motocross.
\end{abstract}

Editor: Asep Hidayat, S.Hut, M.Agr, Ph.D

Korespondensi penulis: Ikhwal Riza Ardiansyah* (E-mail: Ikhwalr@gmail.com)

Kontribusi penulis: IRA: Pengambil, pengolah data, dan penulis karya tulis ilmiah; JBH: Supervisi dalam pengolahan data dan perbaikan karya tulis ilmiah; dan HG: Supervisi dalam pengolahan data dan perbaikan karya tulis ilmiah. 


\section{PENDAHULUAN}

Macan tutul memiliki sembilan subspesies yang tersebar di dunia (Jacobson et al., 2016), diantaranya macan tutul jawa (Panthera pardus melas Cuvier, 1809) yang merupakan satwa karnivora endemik Pulau Jawa. Setelah harimau jawa punah, macan tutul jawa satusatunya kucing besar yang masih hidup dan menduduki puncak rantai makanan yang berperan penting bagi keseimbangan ekosistem. Status konservasi macan tutul jawa yang dikeluarkan oleh International Union for Conservation of Nature \& Natural Resources (IUCN) terus berubah. Pada tahun 1978 berstatus Vulnerable, 1988 berstatus Threatened, 1994 berstatus Indeterminate, 1996 berstatus Endangered, dan 2008 hingga sekarang berstatus Critically Endangered (Ario, Sunarto, \& Sanderson, 2016). Macan tutul jawa termasuk dalam Appendix I Convention on International Trade in Endangered Species of Wild Fauna \& Flora (CITES, 2019) dan terdaftar sebagai satwa yang dilindungi di Indonesia berdasarkan Peraturan Menteri Lingkungan Hidup dan Kehutanan Republik Indonesia Nomor P.106/ Menlhk/Setjen/Kum.1/12/2018 tentang Jenis Tumbuhan dan Satwa yang Dilindungi.

Salah satu habitat alami macan tutul jawa berada di Taman Nasional Gunung Halimun Salak (TNGHS), yaitu areal koridor Gunung Halimun Salak. Sebelum tahun 2003, areal koridor bagian barat dikelola oleh TNGHS, sedangkan bagian timur dikelola oleh Perum Perhutani. Setelah ditetapkannya Surat Keputusan Menteri Kehutanan Nomor 175/KptsII/2003 pada tanggal 10 Juni 2003 mengenai penggabungan kawasan (seluas 113.357 ha), TNGHS memiliki dua ekosistem utama yang dihubungkan oleh koridor, yaitu ekosistem Gunung Halimun dan Gunung Salak.

Koridor yang memiliki panjang kurang lebih $9 \mathrm{~km}$ berfungsi sebagai jembatan bagi kedua ekosistem tersebut agar unsur-unsur yang terdapat di dalamnya tidak terisolasi (Yusuf, 2004). Koridor sangat penting sebagai saluran pertukaran genetik diantara spesies flora dan fauna, terutama satwa yang memiliki wilayah jelajah luas seperti macan tutul jawa. Namun sepertiga areal koridor telah menjadi semak belukar dan sebagian telah menghilang akibat adanya peningkatan populasi manusia dan penggunaan lahan di dalam areal koridor (Yumarni, Alikodra, Prasetyo, \& Soekmadi, 2011). Melihat kondisi tersebut, hal ini akan mendesak keberadaan macan tutul jawa karena ekosistemnya yang terganggu. Tujuan dari penelitian ini yaitu untuk mengetahui bagian-bagian areal koridor yang sesuai sebagai habitat macan tutul jawa.

\section{BAHAN DAN METODE}

\section{A. Waktu dan Lokasi Penelitian}

Penelitian dilaksanakan satu bulan dari Bulan April - Mei 2019 di areal koridor Gunung Halimun-Salak dengan luas kurang lebih 2.600 ha (GHSNPMPJICA, 2006).

\section{B. Bahan dan Alat}

Alat yang digunakan dalam penelitian ini adalah kamera jebak Bushnell model 119440 dan 119740, Global Positioning System (GPS), kamera digital, program software ArcGIS, meteran, tali tambang, pita ukur, tally sheet, alat tulis dan peta kerja penelitian. Objek yang diamati dalam penelitian adalah macan tutul jawa, vegetasi, satwa mangsa, sumber air, dan gangguan habitat yang berada di lokasi penelitian.

\section{Metode Penelitian}

\section{Keberadaan Macan Tutul Jawa}

Metode yang digunakan yaitu survei lapang dan pemasangan kamera jebak. Survei lapang dilakukan pada setiap jalur setapak di setiap grid yang telah ditentukan dengan panjang kurang lebih 2 $\mathrm{km}$. Waktu survei dilakukan sebanyak dua kali, yaitu saat pemasangan dan pelepasan 
kamera jebak. Survei lapang dilakukan berdasarkan perjumpaan langsung dan tidak langsung dengan melihat tandatanda yang ditinggalkan macan tutul jawa, seperti jejak kaki, marking berupa cakaran di pohon (scratch) atau di tanah (scrape), kotoran, air kencing, dan sisa makanan (Malau, 2013). Sedangkan pemasangan dua belas kamera jebak dilakukan secara purposive dengan mempertimbangan keberadaan jejak tidak langsung, dan kelandaian topografi areal disekitarnya. Pemasangan kamera jebak berada pada sepuluh grid yang telah ditentukan. Grid berukuran 2 x $2 \mathrm{~km}^{2}$ berdasarkan pertimbangan ketersediaan jumlah kamera jebak. Kamera jebak dipasang dengan ketinggian sekitar $50 \mathrm{~cm}$ dari atas permukaan tanah agar satwa dapat terekam secara penuh. Kamera jebak dipasang kurang lebih satu bulan dengan mode video selama sepuluh detik dan interval mode satu detik.

\section{Vegetasi}

Pengamatan vegetasi dilakukan untuk mengetahui penggunaannya sebagai habitat bagi macan tutul jawa dan satwa mangsa. Metode yang digunakan adalah jalur berpetak berukuran $20 \times 20 \mathrm{~cm}$ yang dilakukan secara purposive sampling (Sundra, 2016). Penempatan dilakukan pada setiap perjumpaan tidak langsung macan tutul jawa dan satwa mangsa. Data yang diambil untuk setiap tingkat vegetasi adalah jenis dan jumlah setiap jenis. Identifikasi jenis dilakukan dengan wawancara masyarakat lokal dan studi literatur.

\section{Satwa Mangsa}

Data satwa mangsa dikumpulkan dengan metode kamera jebak dan survei lapang (Mustari, Setiawan, \& Rinaldi, 2015). Survei lapang menggunakan metode jelajah (Sundra, 2016). Pengamat berjalan pada jalur yang sudah ada seperti jalan setapak pada setiap grid. Ada 10 jalur dengan panjang kurang lebih $2 \mathrm{~km}$. Pengamatan dimulai dari pukul 07.00 hingga 12.00 WIB. Identifikasi jenis satwa dilakukan dengan wawancara masyarakat lokal dan studi literatur.

\section{Ketersediaan Air}

Selama di lapang dilakukan pencatatan terhadap ketersediaan sumber air. Parameter yang diamati adalah bentuk sumber air dan tipe tutupan lahan tempat ditemukannya sumber air tersebut.

\section{Gangguan dan Ancaman Habitat}

Identifikasi gangguan dilakukan melalui hasil kamera jebak, survei lapang dan wawancara kepada pihak pengelola TNGHS.

\section{Analisis Data}

\section{Identifikasi Individu Macan Tutul Jawa}

Individu macan tutul jawa diidentifikasi berdasarkan pola tutul, jenis kelamin, ciri morfologi, ukuran tubuh dan tanda-tanda spesifik (Olviana, 2011) yang tertangkap dalam kamera jebak.

\section{Analisis Vegetasi}

Data vegetasi diolah untuk mendapatkan nilai-nilai kerapatan dari setiap tingkat vegetasi. Menurut Soerianegara \& Indrawan (2002), perhitungan nilai kerapatan dihitung menggunakan formulasi sebagai berikut:

Kerapatan $(\mathrm{K})=$ jumlah individu $:$ luas contoh

Kerapatan Relatif $(\mathrm{KR})=$ (kerapatan suatu jenis : kerapatan seluruh jenis) $\mathrm{x}$ $100 \%$

\section{Pembuatan Model Kesesuaian Habitat \\ Pembuatan model kesesuaian} habitat dilakukan dengan metode skoring berdasarkan pertimbangan pribadi (personal adjustment). Nilai bobot tinggi diberikan untuk variabel yang dianggap paling memengaruhi kehidupan macan tutul jawa, sedangkan nilai bobot rendah menunjukkan bahwa variabel tersebut 
memiliki pengaruh yang rendah terhadap kehidupan macan tutul jawa. Fungsi dari skoring yaitu untuk merubah semua data yang bersifat kualitatif menjadi kuantitatif. Dalam penentuan kesesuaian habitat di koridor diperlukan beberapa variabel, seperti data kelerengan, ketinggian, tutupan lahan (Nurhuda, Huda, \& Senjani, 2018), satwa, dan jarak dari sumber gangguan (Malau, 2013). Kemudian dilakukan overlay dan pembobotan atau skoring pada setiap variabel. Reklasifikasi dilakukan dengan tujuan untuk menentukan nilai selang klasifikasi kesesuaian habitat yaitu rendah, sedang, dan tinggi (Tabel 1). Rumusan klasifikasi kesesuaian habitat dikembangkan secara spesifik dengan skema pemodelan pada Gambar 1 .

\section{Validasi Model}

Nilai akurasi klasifikasi kesesuaian habitat ditentukan dengan menggunakan validasi model. Validasi dilakukan dengan membandingkan jumlah individu macan tutul jawa yang terdapat di kelas sedang dan tinggi dengan jumlah seluruh individu yang digunakan untuk validasi. Nilai validasi klasifikasi kesesuaian habitat macan tutul jawa menggunakan rumus yang dikembangkan oleh Gunawan (2010) sebagai berikut:

$$
\text { Validasi model }=\frac{n}{N} \times 100 \%
$$

Keterangan (Where):

$\mathrm{n}$ : Jumlah titik lokasi macan tutul di kelas kesesuaian sedang dan tinggi (Number of leopard point locations in medium and high suitability classes)

$\mathrm{N}$ : Jumlah seluruh titik lokasi macan tutul yang ditemukan (The total number of found leopard locations spot)

\section{HASIL DAN PEMBAHASAN}

\section{A. Macan Tutul Jawa}

\section{Sebaran Keberadaan Macan Tutul Jawa}

Berdasarkan hasil survei, terdapat 26 titik indikasi keberadaan macan tutul jawa yang tersebar hampir merata di areal koridor (Gambar 2). Hal ini menandakan bahwa areal koridor masih digunakan oleh macan tutul jawa sebagai wilayah jelajahnya.

Tabel (Table) 1. Rumus penentuan kelas kesesuaian habitat (Formula to determine habitat suitability class).

\begin{tabular}{|c|c|c|}
\hline \multicolumn{2}{|c|}{ Kelas Kesesuaian (Suitability Class) } & Rumus (Formula) \\
\hline & Rendah (Low) & (Min) hingga dengan $($ Min + Mean $) /($ Min $)$ up to $($ Min + Mean $)$ \\
\hline & Sedang (Middle) & $\begin{array}{c}(\text { Min }+ \text { Mean }) \text { hingga dengan }(\text { Max }- \text { Mean }) /(\text { Min }+ \text { Mean }) \text { up } \\
\text { to }(\text { Max }- \text { Mean })\end{array}$ \\
\hline & Tinggi $($ High $)$ & $($ Max - Mean $)$ hingga dengan $($ Max $) /($ Max - Mean $)$ up to $($ Max $)$ \\
\hline \multicolumn{3}{|c|}{ Keterangan (Remarks) : } \\
\hline Min & \multicolumn{2}{|c|}{ Nilai bobot terendah (Lowest value) } \\
\hline Max & \multicolumn{2}{|c|}{ Nilai bobot tertinggi (Highest value) } \\
\hline Mean & \multicolumn{2}{|c|}{$\begin{array}{l}\text { Nilai bobot tertinggi dikurangi nilai terendah kemudian dibagi tiga (The highest value minus the } \\
\text { lowest value then divided by three) }\end{array}$} \\
\hline
\end{tabular}




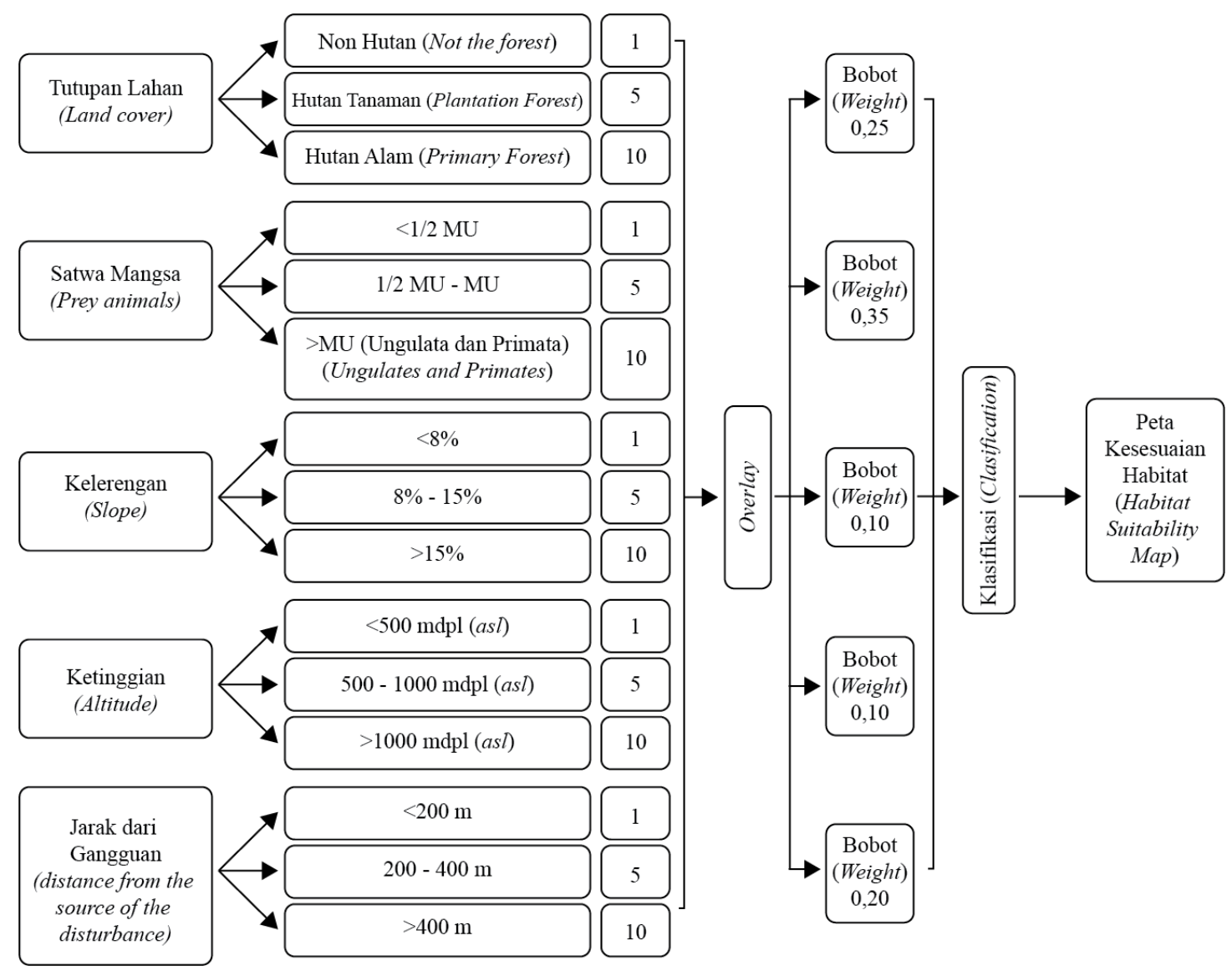

Keterangan (Remarks) :

MU : Mangsa utama (Main Prey animals)

Gambar (Figure) 1. Skema pembuatan model kesesuaian habitat (The making scheme of habitat suitability models)

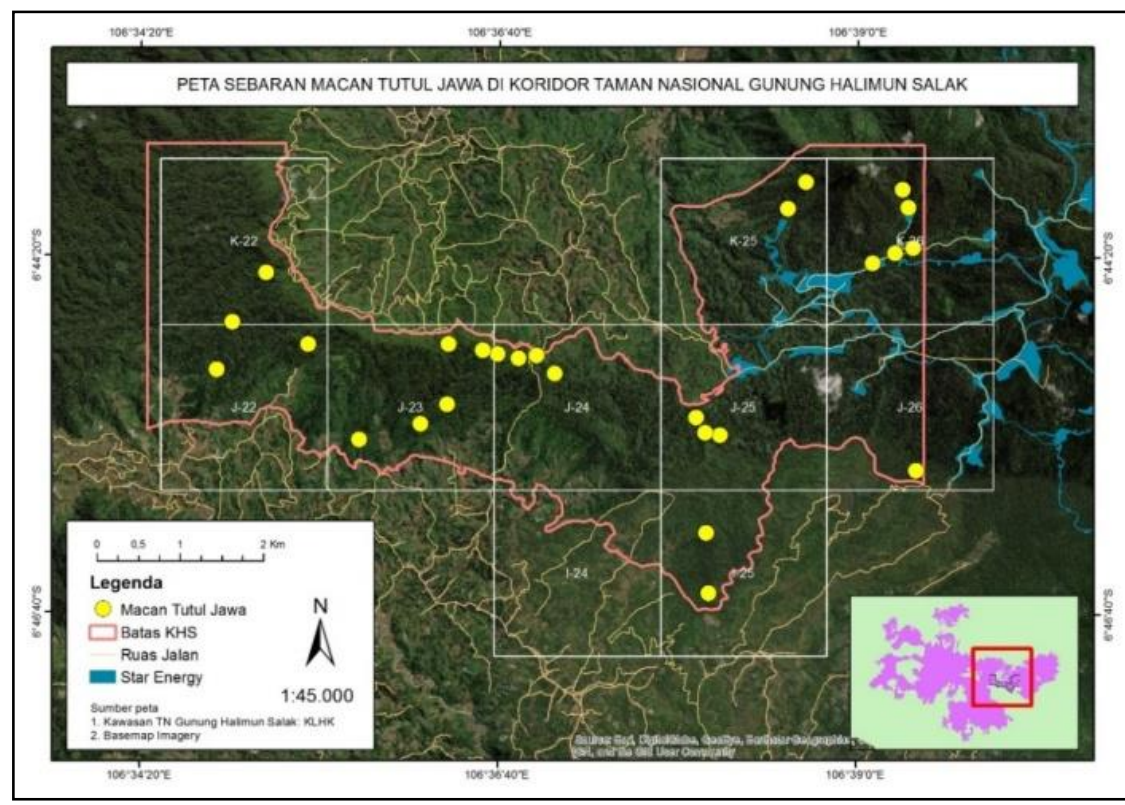

Gambar (Figure) 2. Sebaran macan tutul jawa di koridor (Javan leopard distribution in the corridor) 
Tanda keberadaan macan tutul jawa yang ditemukan berupa jejak kaki, bekas rebahan, feses, air kencing, cakaran di tanah dan pohon. Pada umumnya tanda yang paling banyak (70\%) ditemukan adalah cakaran di tanah (Gambar 3). Ditemukan 53 titik cakaran di tanah, dengan rata-rata panjang $20-45 \mathrm{~cm}$ dan lebar 13 - $22 \mathrm{~cm}$. Sedangkan temuan terbesar kedua adalah jejak kaki. Ditemukan 17 titik jejak kaki dengan ratarata berukuran $8 \times 6 \mathrm{~cm}$.

Menurut Gunawan (2010), batas teritori secara teratur ditandai dengan urin, feces, kemunculan/kehadiran, cakaran di tanah dan pohon. Tanda-tanda tersebut merupakan salah satu cara komunikasi yang penting antar individu macan tutul jawa lainnya. Berdasarkan hasil kamera jebak, tanda-tanda tersebut kurang berpengaruh terhadap individu macan tutul jawa lainnya. Hal ini dibuktikan temuan individu yang berbeda pada lokasi yang sama.

\section{Identifikasi Individu Macan Tutul Jawa}

Berdasarkan hasil dari pengamatan 12 kamera jebak, didapatkan 25 rekaman macan tutul jawa yang terdiri dari 8 video macan tutul dan 17 video macan kumbang. Hasil analisa menunjukkan rekaman kamera jebak merepresentasikan satu individu macan tutul dan tiga individu macan kumbang. Faktor pembeda pola tutul tidak bisa dilakukan karena keterbatasan kualitas video yang dihasilkan, sehingga hanya dilakukan berdasarkan ukuran tubuh dan tanda spesifik (Tabel 2).

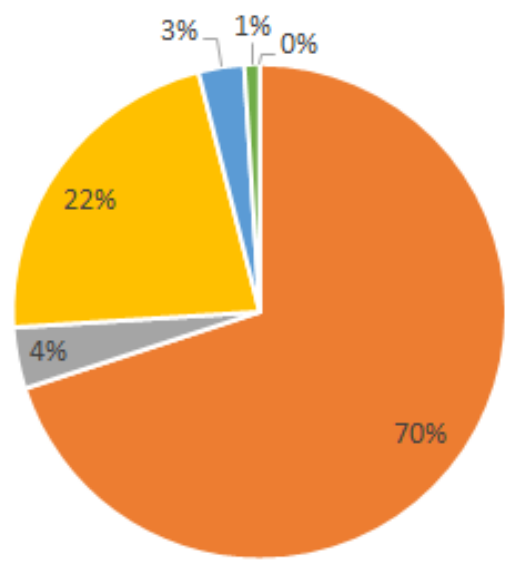

$$
\begin{aligned}
& \text { - Cakaran pohon (Scratch) } \\
& \text { - Cakaran tanah (Scrape) } \\
& \text { = Feses (Faeces) } \\
& \text { " Jejak kaki (Footprint) } \\
& \text { - Air kencing (Urine) } \\
& \text { - Bekas rebahan (Sleep trace) }
\end{aligned}
$$

Gambar (Figure) 3. Temuan tidak langsung macan tutul jawa (Indirect observation of Javan leopards)

Tabel (Table) 2. Pembeda setiap individu macan tutul jawa (The distinction of each individual Javan leopard).

\begin{tabular}{cccc}
\hline $\begin{array}{c}\text { Individu } \\
\text { (Individual) }\end{array}$ & Jenis Kelamin (Sex) & $\begin{array}{c}\text { Kelas Umur (Age } \\
\text { Class) }\end{array}$ & Tanda Spesifik (Specific Sign) \\
\hline Tutul (A) & Jantan (Male) & Dewasa (Adult) & Normal (Normal) \\
Kumbang (1) & Jantan (Male) & $\begin{array}{c}\text { Dewasa (Adult) } \\
\text { Dewasa muda } \\
\text { (Young adult) }\end{array}$ & Normal (Normal) \\
Kumbang (2) & Jantan (Male) & Normal (Normal) \\
Kumbang (3) & Jantan (Male) & Dewasa (Adult) & $\begin{array}{c}\text { Luka bagian kiri tubuh (Wound } \\
\text { on the left side of the body) }\end{array}$ \\
\hline
\end{tabular}


Individu macan Tutul (A) dan Kumbang (1) lebih sering ditemukan di jalur yang sama, sedangkan macan Kumbang (2) dan Kumbang (3) hanya terekam satu kali (Gambar 4). Temuan marking yang merata di areal koridor tidak berpengaruh terhadap keberadaan antar individu jantan lainnya. Keempat individu macan tutul jawa tersebut saling overlap pada wilayah jelajahnya (Tabel 3).

Meskipun demikian, berdasarkan hasil kamera jebak macan tutul jawa menggunakan waktu yang berbeda-beda. Hal ini bertujuan untuk menghindari pertengkaran antara sesama individu jantan dalam perebutan wilayah. Sesuai dengan pendapat Mizutani \& Jewell (1998) yang mengatakan bahwa macan tutul jawa merupakan satwa teritorial sehingga hanya akan overlap atau bertemu dengan lawan jenis.

\section{B. Kondisi Habitat}

1. Vegetasi Penting Macan Tutul Jawa

Tingkat vegetasi yang penting bagi habitat macan tutul jawa adalah tingkat tumbuhan bawah dan strata pohon (Yanti, 2011). Menurut Gunawan (2010), bagi macan tutul jawa vegetasi seringkali lebih penting strukturnya daripada jenisnya, sehingga nilai kerapatan sudah mewakili untuk mengetahui penggunaan vegetasi bagi macan tutul jawa. Berdasarkan hasil pengamatan, nilai kerapatan tumbuhan bawah di setiap tutupan lahan relatif masih tinggi (Tabel 4).

Jenis tumbuhan bawah yang memiliki kerapatan relatif paling tinggi adalah rumput bambu (Lophatherum gracile) sebesar 26,82\%, diikuti harendong bulu (Clidemia hirta) sebesar $16,12 \%$ dan paku andam (Dicranopteris linearis) sebesar 5,43\%. Menurut Yanti (2011) kondisi tumbuhan bawah yang rapat dan pohon yang tidak terlalu rapat membantu memudahkan macan tutul jawa untuk bergerak memburu satwa mangsa. Hasil penelitian menunjukkan bahwa tanda-tanda keberadaan satwa mangsa utama (sarang dan jejak kaki babi hutan) tersebar pada tutupan lahan hutan sekunder, hutan tanaman dan semak belukar. Keberadaan hewan mangsa di setiap tipe tutupan lahan berkorelasi dengan keberadaan macan tutul jawa. Sebanyak 23 titik ditemukan di hutan sekunder, 2 titik di hutan tanaman, dan 1 titik di semak belukar (Tabel 5).

Tabel (Table) 3. Hasil rekaman kamera jebak macan tutul jawa (The recod results of the camera traps of the Javan leopard).

\begin{tabular}{|c|c|c|c|c|c|c|}
\hline $\begin{array}{c}\text { Tanggal } \\
\text { (Date) }\end{array}$ & $\begin{array}{l}\text { Waktu } \\
\text { (Time) }\end{array}$ & $\begin{array}{c}\text { Tutul } \\
\text { (A) }\end{array}$ & Kumbang (1) & Kumbang (2) & Kumbang (3) & Petak (Grid) \\
\hline $6-4-2019$ & 16.00 & & & $\mathrm{X}$ & & J.24 \\
\hline $8-4-2019$ & 11.08 & & $\mathrm{X}$ & & & J.25 \\
\hline $12-4-2019$ & 17.55 & $\mathrm{X}$ & & & & J.25 \\
\hline $15-4-2019$ & 07.59 & & $\mathrm{X}$ & & & K.22 \\
\hline $15-4-2019$ & 16.09 & & $\mathrm{X}$ & & & $\mathrm{J} .23$ \\
\hline $18-4-2019$ & 20.52 & $\mathrm{X}$ & & & & J.25 \\
\hline 25-4-2019 & 04.12 & & $\mathrm{X}$ & & & $\mathrm{J} .23$ \\
\hline $25-4-2019$ & 03.18 & & $\mathrm{X}$ & & & J.24 \\
\hline $28-4-2019$ & 10.23 & & $X$ & & & $\mathrm{~J} .23$ \\
\hline $9-5-2019$ & 03.48 & $\mathrm{X}$ & & & & J.23 \\
\hline $9-5-2019$ & 18.04 & & $\mathrm{X}$ & & & $\mathrm{J} .23$ \\
\hline $9-5-2019$ & 16.44 & & $\mathrm{X}$ & & & $\mathrm{J} .23$ \\
\hline $11-5-2019$ & 01.07 & $\mathrm{X}$ & & & & К.25 \\
\hline $12-5-2019$ & 16.18 & $\mathrm{X}$ & & & & К.26 \\
\hline $15-5-2019$ & 03.07 & $\mathrm{X}$ & & & & J.23 \\
\hline $21-5-2019 y$ & 10.29 & & $\mathrm{X}$ & & & К. 25 \\
\hline $21-5-2019 y$ & 10.24 & & $\mathrm{X}$ & & & K.25 \\
\hline $18-6-2019$ & 21.04 & & & & $\mathrm{X}$ & К. 25 \\
\hline $18-6-2019$ & 20.59 & & & & $\mathrm{X}$ & К. 25 \\
\hline
\end{tabular}




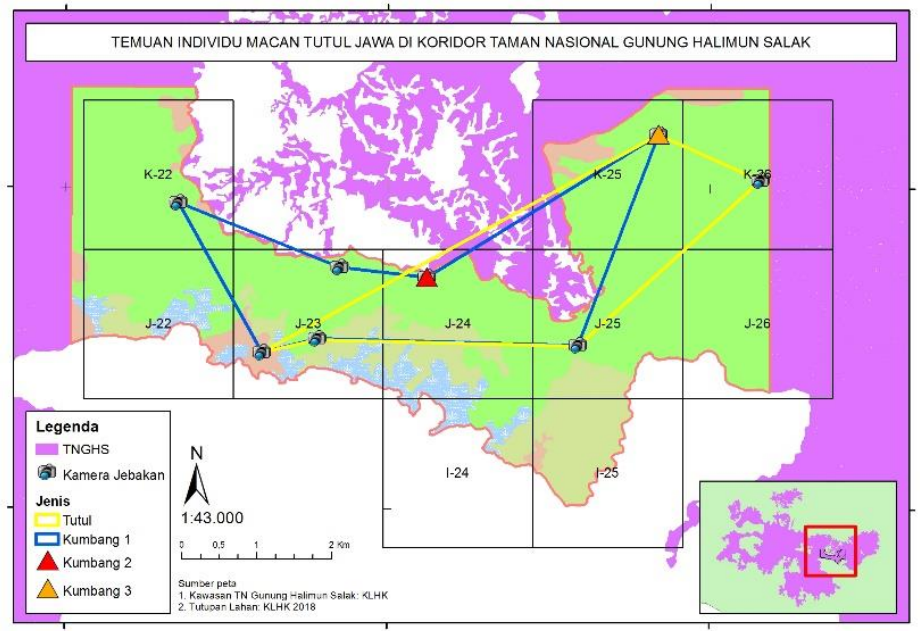

Gambar (Figure) 4. Perjumpaan setiap individu macan tutul jawa di koridor (Individual Javan leopard encountered in the corridor).

Tabel (Table) 4. Kerapatan vegetasi setiap tutupan lahan (Vegetation density of each land cover)

\begin{tabular}{|c|c|c|c|c|}
\hline \multirow[b]{2}{*}{ No } & \multirow[b]{2}{*}{ Tingkat Vegetasi (Vegetation Level) } & \multicolumn{3}{|c|}{$\begin{array}{c}\text { Kerapatan (Density), individu/ha } \\
\text { (Individual/ha) }\end{array}$} \\
\hline & & $\begin{array}{c}\text { Hutan } \\
\text { Sekunder } \\
\text { (Secondary } \\
\text { Forest) }\end{array}$ & $\begin{array}{c}\text { Hutan } \\
\text { Tanaman } \\
\text { (Plantation } \\
\text { Forest) }\end{array}$ & $\begin{array}{c}\text { Semak } \\
\text { Belukar } \\
\text { (Shrubs) }\end{array}$ \\
\hline 1 & $\begin{array}{l}\text { Semai (Seedlings), Tumbuhan Bawah } \\
\text { (Undergrowth) }\end{array}$ & 72.250 & 44.500 & 48.667 \\
\hline 2 & Pancang (Sapling) & 960 & 1.840 & 1.465 \\
\hline 3 & Tiang (Poles) & 410 & 340 & 367 \\
\hline 4 & Pohon (Tree) & 178 & 101 & 58 \\
\hline
\end{tabular}

Tabel (Table) 5. Sebaran macan tutul jawa di berbagai tipe tutupan lahan (Javan leopard distribution in various types of land cover).

\begin{tabular}{clcccc}
\hline No & $\begin{array}{c}\text { Tipe Tutupan } \\
\text { Lahan (Land } \\
\text { Cover Type) }\end{array}$ & $\begin{array}{c}\text { Luas (Area), } \\
\text { ha }\end{array}$ & $\begin{array}{c}\text { Persentase } \\
(\text { Percentage }), \\
\%\end{array}$ & $\begin{array}{c}\text { Jumlah Posisi } \\
\text { Ditemuakan Macan } \\
\text { Tutul Jawa (Total spot } \\
\text { of Javan Leopards } \\
\text { Finding), Titik (Point) }\end{array}$ & $\begin{array}{c}\text { Persentase } \\
(\text { Percentage), } \\
\%\end{array}$ \\
\hline 1 & $\begin{array}{l}\text { Hutan Sekunder } \\
\text { (Secondary Forest) }\end{array}$ & $1.882,28$ & 73,58 & 23 & 88,46 \\
2 & $\begin{array}{l}\text { Hutan Tanaman } \\
\text { (Plantation Forest) }\end{array}$ & 374,15 & 14,62 & 2 & 7,69 \\
3 & $\begin{array}{l}\text { Semak Belukar } \\
\text { (Shrubs) }\end{array}$ & 133,67 & 5,22 & 1 & 3,85 \\
4 & Pertanian (Farm) & 168,21 & 6,58 & 0 & 0 \\
\hline & Jumlah (Total) & $\mathbf{2 . 5 5 8 , 3 1}$ & $\mathbf{1 0 0 , 0 0}$ & $\mathbf{2 6}$ & $\mathbf{1 0 0 , 0 0}$ \\
\hline
\end{tabular}


Kondisi vegetasi hubungannya dengan lindungan (cover) macan tutul jawa. Keberadaan lindungan berfungsi sebagai pendukung keberlangsungan hidup macan tutul jawa. Lindungan dibutuhkan satwa sebagai tempat perlindungan dari terik matahari, hujan, dan ancaman. Bentuk lindungan dapat berbeda-beda tergantung pada kondisi vegetasi di alam. Berdasarkan hasil pengamatan, ada tiga bentuk lindungan macan tutul jawa yang ditemukan di areal koridor (Tabel 6). Tajuk pohon dan rumpun bambu dapat berfungsi sebagai tempat istirahat dan melindungi diri dari sinar matahari, sedangkan goa yang ditemukan dapat berpotensi sebagai tempat mengasuh dan berlindung anak macan tutul jawa.

\section{Vegetasi Pakan Satwa Mangsa}

Beberapa jenis tumbuhan pakan satwa mangsa yang ditemukan pada setiap tutupan lahan dapat dilihat pada Tabel 7.

Tabel (Table) 6. Bentuk lindungan yang ditemukan pada setiap tutupan lahan (The form of cover found on each land cover).

\begin{tabular}{ll}
\hline \multicolumn{1}{c}{ Tipe Tutupan Lahan (Land Cover Type) } & \multicolumn{1}{c}{ Bentuk Lindungan (Cover form) } \\
\hline Hutan sekunder (Secondary forest) & Tajuk pohon (Canopy tree) \\
& Rumpun bamboo (Bamboo clump) \\
& Goa (Cave) \\
Hutan tanaman (Plantation forest) & Tajuk pohon (Canopy tree) \\
Semak belukar (Shrubs) & Tajuk pohon (Canopy tree) \\
\hline
\end{tabular}

Tabel (Table) 7. Jenis tumbuhan pakan satwa mangsa di koridor (Types of forage plants for prey animals in the corridor).

\begin{tabular}{clccccc}
\hline \multirow{2}{*}{ No } & \multirow{2}{*}{ Jenis (Species) } & Satwa (Animals) & \multicolumn{3}{c}{$\begin{array}{c}\text { Tipe Tutupan Lahan } \\
\text { (Land cover type) }\end{array}$} \\
\cline { 4 - 7 } & & HS & HT & SB & P \\
\hline 1 & Hamerang (Ficus padana) & Primata (Primate) & $\checkmark$ & $\checkmark$ & - & - \\
2 & Puspa (Schima wallichii) & Primata (Primate) & $\checkmark$ & $\checkmark$ & $\checkmark$ & - \\
3 & Manii (Maesopsis eminii) & Primata (Primate) & $\checkmark$ & $\checkmark$ & - & - \\
4 & Rasamala (Altingia excelsa) & Primata(Primate) & $\checkmark$ & - & - & - \\
5 & Saninten (Castanopsis javanica) & Primata (Primate), Babi Hutan & $\checkmark$ & - & - & - \\
6 & Markisa (Passiflora edulis) & (Wild boar) & & & & - \\
7 & Huru sp & Primata (Primate) & $\checkmark$ & $\checkmark$ & - & - \\
8 & Kileho (Saurauia pendula) & Primata (Primate) & $\checkmark$ & $\checkmark$ & - & - \\
9 & Mara (Macaranga tanarius) & Primata (Primate) & $\checkmark$ & $\checkmark$ & - & - \\
10 & Kihujan (Engelhardtia serrata) & Primata (Primate) & $\checkmark$ & - & - & - \\
11 & Kaliandra (Calliandra calothyrsus) & Primata (Primate) & $\checkmark$ & - & $\checkmark$ & - \\
12 & Tumbuhan bawah (Undergrowth) & Kijang (Deer), Kancil Mouse & $\checkmark$ & $\checkmark$ & $\checkmark$ & $\checkmark$ \\
\hline
\end{tabular}

Keterangan (Remarks) :

HS : Hutan Sekunder (Secondary Forest)

HT : Hutan Tanaman (Plantation forest)

SB : Semak Belukar (Shrubs)

$\mathrm{P} \quad$ : Pertanian (Agriculture)

$\checkmark \quad$ : Ada (Present)

- $\quad$ : Tidak ada (Absent) 
Berdasarkan Tabel 7, sebanyak 12 jenis tumbuhan pakan satwa mangsa tersebar pada tipe tutupan lahan. Semua jenis tumbuhan pakan (12 jenis) ditemukan pada hutan sekunder yang merupakan habitat utama satwa mangsa macan tutul jawa (Tabel 6 dan 7). Kerapatan pohon yang tinggi bagi satwa mangsa seperti primata merupakan habitat untuk kehidupannya yang arboreal sebagai tempat berlindung, berkembang biak, dan mencari makan (Dinata \& Sugardjito, 2008). Berdasarkan hasil kamera jebak pada tutupan lahan semak belukar terekam surili (Presbytis comata) berjalan di lantai hutan. Kerapatan pohon semak belukar yang lebih kecil daripada tutupan lahan lainnya cenderung membuat satwa primata harus turun ke lantai hutan.

\section{Ketersediaan Satwa Mangsa}

Berdasarkan pencatatan hasil kamera jebak dan survei lapang, teridentifikasi 18 jenis satwa, terdiri dari 13 jenis kelompok mamalia dan 5 jenis kelompok burung (Tabel 8). Satwa-satwa tersebut tersebar di berbagai tipe tutupan lahan di areal koridor, dan terbanyak ditemukan di hutan sekunder (17 jenis).

Tabel (Table) 8. Perjumpaan satwa yang berpotensi menjadi mangsa di setiap tipe tutupan lahan di koridor (Encounter of potential prey animals in each type of land cover in the corridor).

\begin{tabular}{clcccc}
\hline \multirow{2}{*}{ No } & \multicolumn{2}{c}{ Jenis (Species) } & \multicolumn{3}{c}{ Tipe Tutupan Lahan (Land cover type) } \\
\cline { 3 - 6 } & & HS & HT & SB & P \\
\hline 1 & Babi Hutan (Sus scrofa) & $\checkmark$ & $\checkmark$ & $\checkmark$ & $\checkmark$ \\
2 & Anjing (Canis lupus) & $\checkmark$ & - & $\checkmark$ & $\checkmark$ \\
3 & Kucing Hutan (Prionailurus bengalensis) & $\checkmark$ & - & - & - \\
4 & Kijang (Muntiacus muntjak) & $\checkmark$ & - & - & - \\
5 & Pelanduk Kancil (Tragulus javanicus) & $\checkmark$ & - & - & - \\
6 & Musang Rase (Viverricula indica) & $\checkmark$ & - & - & - \\
7 & Musang Pandan (Paradoxurus hermaphroditus) & $\checkmark$ & - & - & - \\
8 & Tupai (Tupaia sp.) & $\checkmark$ & - & - & $\checkmark$ \\
9 & Sigung (Mydaus javanensis) & $\checkmark$ & - & - & - \\
10 & Surili (Presbytis comata) & $\checkmark$ & - & $\checkmark$ & - \\
11 & Owa Jawa (Hylobates moloch) & $\checkmark$ & - & - & - \\
12 & Lutung Jawa (Trachypithecus auratus) & $\checkmark$ & - & - & - \\
13 & Monyet Ekor Panjang (Macaca fascicularis) & $\checkmark$ & - & - & - \\
14 & Puyuh Gonggong Biasa (Arborophila javanica) & $\checkmark$ & $\checkmark$ & - & - \\
15 & Ayam Hutan Merah (Gallus gallus) & $\checkmark$ & $\checkmark$ & - & - \\
16 & Delimukan Zamrud (Chalcophaps indica) & $\checkmark$ & $\checkmark$ & - & - \\
17 & Paok Pancawarna (Pitta guajana) & - & $\checkmark$ & - & - \\
18 & Elang (Ictinaetus malayensis) & $\checkmark$ & $\checkmark$ & - & $\checkmark$ \\
\hline Keterangan (Remarks) : & & & & \\
HS & : Hutan Sekunder (Secondary Forest) & & & \\
HT & : Hutan Tanaman (Plantation forest) & & & \\
SB & : Semak Belukar (Shrubs) & & & \\
P & : Pertanian (Agriculture) & & & \\
$\checkmark$ & : Ada (Present) & & & \\
- & : Tidak ada (Absent) & & &
\end{tabular}


Menurut Shaw (1985), komponen utama bagi predator seperti macan tutul adalah makanan atau satwa mangsa. Hasil penelitian menunjukkan bahwa keberadaan macan tutul jawa lebih banyak ditemukan pada tipe tutupan lahan hutan sekunder (Tabel 5). Keberadaan macan tutul jawa sangat berkolerasi dengan jumlah sumber pakan satwa mangsa dan jenis satwa mangsa (Table 7 dan 8). Babi hutan menjadi mangsa paling potensial (Tabel 7), dikarenakan beberapa jejak kaki babi hutan, bulu babi hutan pada feses macan tutul jawa, dan sarang babi hutan ditemukan tersebar merata di areal koridor.

\section{Ketersediaan Air}

Areal koridor halimun salak masih memiliki sumber air yang dapat ditemukan di seluruh tipe tutupan lahan. Bentuk sumber air yang ditemukan adalah sungai, parit, dan kubangan saat musim hujan datang. Tanda-tanda keberadaan macan tutul jawa dan satwa mangsa seperti babi juga ditemukan di dekat sumber air. Sumber air menjadi salah satu tempat berburu yang mudah bagi macan tutul jawa karena merupakan tempat satwa berkumpul (Gunawan, 2010).

Bagi macan tutul jawa, air bukan komponen utama dalam pemilihan habitat. Berbeda dengan harimau yang sangat bergantung pada ketersediaan air di habitatnya (Olviana, 2011), sedangkan macan tutul jawa memiliki sifat yang lebih toleran terhadap temperatur ekstrim dan lingkungan kering (Santiapillai \& Ramono, 1992). Macan tutul jawa dapat bertahan tidak minum air selama 2-3 hari karena sudah terpenuhi saat memakan satwa mangsa yang mengandung cukup banyak air (Grzimek, 1975). Namun air tetap memegang peranan penting bagi kehidupan mamalia sebagai sumber air minum dan untuk melakukan proses metabolisme dalam tubuh (Gunawan, 2010).

\section{Kesesuaian Habitat}

Hasil overlay dari kelima variabel ditemukan bahwa kelas kesesuaian yang paling tinggi adalah seluas $1.247,41$ ha (49\%) yang didominasi tutupan lahan hutan sekunder (Tabel 9). Kawasan kelas kesesuaian ini memiliki vegetasi yang rapat dan berguna sebagai lindungan macan tutul jawa. Namun, pada kelas kesesuaian sedang, jumlah titik perjumpaan macan tutul jawa paling banyak ditemukan. Hal ini disebabkan karena ketersediaan satwa mangsa yang cukup, sehingga masih relevan digunakan macan tutul jawa sebagai wilayah jelajahnya terutama aktivitas mencari mangsa. Berdasarkan hasil kamera jebak, frekuensi gangguan seperti aktivitas manusia masuk hutan masih tinggi antara 2 - 4 kali per minggu. Pada kelas kesesuaian rendah, umumnya berupa lahan ladang, sawah, dan bahkan terdapat rumah masyarakat. Macan tutul jawa relatif akan menghindari daerah tersebut akibat intensitas aktivitas masyarakat yang tinggi.

Nilai validasi model kesesuaian habitat menggunakan 26 titik sebaran macan tutul jawa adalah $100 \%$. Menurut Dhistira (2011) tingkat kepercayaan >85\% menunjukkan bahwa model kesesuaian habitat tersebut diterima. Peta kesesuaian habitat macan tutul jawa yang dihasilkan dari penelitian ini terlihat pada Gambar 5.

\section{Gangguan Habitat}

\section{Aktivitas Masyarakat Masuk Hutan}

Berdasarkan hasil kamera jebak, perolehan rekaman video yang paling banyak adalah aktivitas peneliti (75 video) dan berburu (42 video) (Tabel 10). Peneliti terekam hanya satu kali, namun didapatkan jumlah video terbanyak disebabkan peneliti beraktivitas tepat di depan kamera. 
Tabel (Table) 9. Klasifikasi kesesuaian habitat macan tutul jawa di koridor (The classification of Javan leopard habitat suitability in the corridor).

\begin{tabular}{ccccc}
\hline $\begin{array}{c}\text { Kelas Kesesuaian / } \\
\text { Suitability class }\end{array}$ & $\begin{array}{c}\text { Interval Skor / } \\
\text { Score Interval }\end{array}$ & $\begin{array}{c}\text { Jumlah Titik/ } \\
\text { Number of } \text { spot }\end{array}$ & Luas / area (ha) & $\begin{array}{c}\text { Persentase / } \\
\text { percentage } \\
(\%)\end{array}$ \\
\hline Rendah / low & $0,1-3,4$ & 0 & 291,79 & 11 \\
Sedang / middle & $3,4-6,7$ & 18 & $1.019,11$ & 40 \\
Tinggi / high & $6,7-10$ & 8 & $1.247,41$ & 49 \\
\hline Jumlah & & $\mathbf{2 6}$ & $\mathbf{2 . 5 5 8 , 3 1}$ & $\mathbf{1 0 0}$ \\
\hline
\end{tabular}

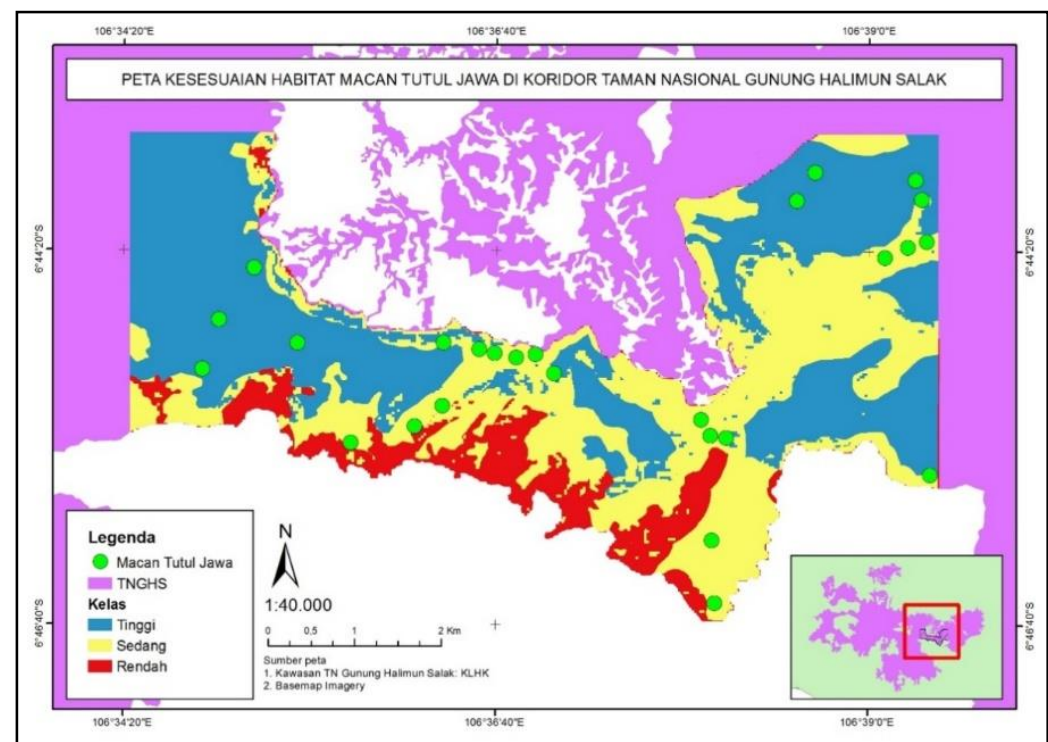

Gambar (Figure) 5. Peta kesesuaian habitat macan tutul jawa di koridor (Map of Javan leopard habitat suitability in the corridor)

Tabel (Table) 10. Bentuk kegiatan masyarakat masuk hutan (Form of community activities in the forest).

\begin{tabular}{|c|c|c|c|}
\hline $\begin{array}{l}\text { Bentuk Kegiatan } \\
\text { (Activitiesy) }\end{array}$ & $\begin{array}{c}\text { Jumlah } \\
\text { Rekaman } \\
\text { Video (The } \\
\text { number of } \\
\text { recorded } \\
\text { videos) }\end{array}$ & $\begin{array}{c}\text { Persentase } \\
(\text { percentage }) \\
\%\end{array}$ & Keterangan (Remarks) \\
\hline Berburu (Hunt) & 42 & 29,58 & $\begin{array}{l}\text { Membawa senjata, kantong, sangkar burung, } \\
\text { anjing pemburu (Bring weapons, pockets, bird } \\
\text { cages, hunting dogs) }\end{array}$ \\
\hline $\begin{array}{l}\text { Mengambil rumput } \\
\text { (Taking grass) }\end{array}$ & 12 & 8,45 & Membawa rumput (Bring grass) \\
\hline $\begin{array}{l}\text { Mencari bibit } \\
\text { (Collecting seeds) }\end{array}$ & 2 & 1,41 & $\begin{array}{l}\text { Membawa clurit dan kantong bibit (Bring sickle } \\
\text { and seed bags) }\end{array}$ \\
\hline $\begin{array}{l}\text { Peneliti (The } \\
\text { researcher) }\end{array}$ & 75 & 52,82 & Membawa kamera (Bring camera) \\
\hline $\begin{array}{l}\text { Pengontrol saluran } \\
\text { udara tegangan ekstra } \\
\text { tinggi (Extra high } \\
\text { voltage air duct } \\
\text { controller) }\end{array}$ & 11 & 7,75 & $\begin{array}{l}\text { Berpakaian berlogo PLN (Dressed in the PLN } \\
\text { logo) }\end{array}$ \\
\hline Total (Amount) & 142 & 100 & \\
\hline
\end{tabular}


Hasil wawancara dengan pihak taman nasional, masyarakat melakukan perburuan kumbang atau burung untuk dikoleksi dan dijual. Berdasarkan Tabel 11, diketahui bahwa macan tutul jawa juga beraktivitas di areal koridor pada jam aktivitas masyarakat masuk hutan yaitu pukul 06.00 - 16.00 WIB, sehingga kondisi ini akan mengancam keberadaan antara macan tutul jawa dan masyarakat.

\section{Penebangan Liar}

Bekas penebangan atau perusakan tumbuhan yang ditemukan di areal koridor adalah buah rotan dan kayu. Temuan bekas tebangan kayu besar (diameter sekitar $40 \mathrm{~cm}$ ) di areal koridor merupakan tebangan tahun 2016. Menurut pengelola taman nasional, penebangan pada tingkat pohon sudah jarang ditemukan. Sementara, penebangan pada tingkat pancang dan tiang masih banyak ditemukan karena masih digunakan masyarakat untuk kayu bakar atau pembuatan bivak saat berburu. Kerusakan hutan di TNGHS semakin parah akibat penebangan secara liar (Arifanti, Dharmawan, \& Wicaksono, 2014). Sejak berlakunya SK. Menteri Kehutanan No.282 tahun 1992 yang mengacu pada UU Ketentuan-ketentuan Pokok Kehutanan No.5/1967 dan UU Konservasi dan Sumberdaya Hayati No.5/1990, Balai Taman Nasional mulai membatasi segala kegiatan masyarakat antara lain pelarangan pengambilan kayu bakar, tanaman untuk obat-obatan, dan hasil hutan lainnya (Marina \& Dharmawan, 2011). Apabila pengambilan kayu tingkat pancang dan tiang terus terjadi di areal koridor, maka akan berpengaruh terhadap habitat dan jumlah populasi satwa masa mendatang.

\section{Kegiatan Motor Kros}

Pada areal koridor terdapat dua jalur motokros yang aktif digunakan, panjang jalur kurang lebih 3 - $4 \mathrm{~km}$. Berdasarkan wawancara terhadap kepala Resort Gunung Kendeng, terdapat dua kali aktivitas motokross ilegal di dalam hutan pada tahun 2019. Menurut Ladyfandela, Novarino, \& Nurdin (2018), satwa memiliki pendengaran yang lebih peka daripada manusia. Suara keras yang ditimbulkan motor akan sangat mempengaruhi satwa liar dan ekosistem yang ada di dalam hutan (Sahrullah, 2009). Dampak langsung yang diakibatkan kegiatan ini akan menimbulkan rasa takut bagi satwa di areal koridor khususnya macan tutul jawa. Dampak tidak langsung yang akan terjadi berpotensi mengakibatkan macan tutul jawa akan terfragmentasi pada wilayah tertentu dan sulit untuk mencari pasangan pada wilayah hutan lainnya.

Tabel (Table) 11. Waktu aktif masyarakat dan macan tutul jawa berdasarkan hasil kamera jebak (Active time of the community and Javane leopards based on the results of camera traps).

\begin{tabular}{|c|c|c|c|c|c|c|c|c|c|c|c|c|c|c|c|c|c|c|c|c|c|c|c|c|}
\hline \multirow{2}{*}{$\begin{array}{l}\text { Nama } \\
\text { (name) }\end{array}$} & \multicolumn{24}{|c|}{ Waktu (time) } \\
\hline & 1 & 2 & 3 & 4 & 5 & 6 & 7 & 8 & 9 & 10 & 11 & 12 & 13 & 14 & 15 & 16 & 17 & 18 & 19 & 20 & 21 & 22 & 23 & 24 \\
\hline $\mathrm{A}$ & - & - & - & - & - & $\mathrm{x}$ & $\mathrm{x}$ & $\mathrm{x}$ & $\mathrm{x}$ & $\mathrm{X}$ & $\mathrm{x}$ & $\mathrm{x}$ & $\mathrm{X}$ & $\mathrm{X}$ & $\mathrm{x}$ & $\mathrm{x}$ & $\mathrm{X}$ & - & - & - & - & - & - & - \\
\hline B & - & - & $\mathrm{x}$ & $\mathrm{x}$ & $\mathrm{x}$ & - & $\mathrm{x}$ & $\mathrm{x}$ & $\mathrm{x}$ & $\mathrm{x}$ & $\mathrm{x}$ & $\mathrm{x}$ & - & - & - & $\mathrm{x}$ & $\mathrm{x}$ & $\mathrm{x}$ & $\mathrm{x}$ & $\mathrm{x}$ & $\mathrm{x}$ & - & - & - \\
\hline
\end{tabular}

Keterangan (Remarks) :

A: Masyarakat (People)

B: Macan tutul jawa (Javan leopard) $\mathrm{x}$ : Terekam (Recorded)

- : Tidak terekam (Not recorded) 
Berdasarkan hasil pengamatan, tanda-tanda kehadiran macan tutul jawa dan satwa lainnya masih dapat ditemukan pada jalur motokross tersebut. Kondisi ini akan mendesak keberadaan satwa apabila aktivitas bermotor yang masuk dalam hutan sering terjadi. Dengan demikian maka patroli secara rutin dari pihak Taman Nasional Gunung Halimun Salak khususnya pengelola Resort Gunung Kendeng perlu dilakukan.

\section{Saluran Udara Tegangan Ekstra Tinggi (SUTET) \\ Ada empat tiang SUTET yang} melintas dari selatan ke utara di areal koridor. Aktivitas pekerja yang bertugas di sekitar jalur SUTET akan mengganggu keberadaan satwa didalamanya karena sifat satwa yang peka terhadap kehadiran manusia (Ladyfandela, Novarino, \& Nurdin, 2018). Hasil kamera jebak, macan tutul jawa terekam pukul 17.00 WIB dan 03.00 WIB untuk menghindari keberadaan manusia. Macan tutul jawa beraktivitas di sekitar lokasi SUTET untuk mencari mangsa seperti babi hutan.

\section{E. Implikasi Pengelolaan}

Berdasarkan hasil penelitian diketahui bahwa $49 \%$ luasan areal koridor halimun salak memiliki kesesuaian habitat yang tinggi, dan $40 \%$ memiliki kesesuaian habitat yang sedang bagi macan tutul jawa. Kelas kesesuaian sedang masih tergolong memiliki tingkat kerawanan yang tinggi, namun macan tutul jawa juga masih menggunakan lokasi tersebut. Dalam pengelolaan areal koridor, aspek keamanan bagi habitat satwa perlu diperhatikan. Rekomendasi tindakan yang perlu dilakukan berdasarkan kelas kesesuiannya adalah sebagai berikut:

\section{Kesesuaian tinggi}

- Monitoring secara berkala, khususnya potensi ancaman terhadap satwa dan habitatnya seperti perburuan dan pembukaan lahan.
- Mempertahankan kekompakan habitatnya agar tidak terfragmentasi lagi.

\section{Kesesuaian sedang}

- Peningkatan vegetasi asli sebagai habitat dan pakan satwa lainnya.

- Patroli secara berkala terhadap gangguan seperti aktivitas bermotor dan intensitas masyarakat masuk hutan yang masih tinggi.

- Penutupan jalan bekas motokross menggunakan plang untuk mencegah akses motor masuk kedalam hutan kembali.

- Penanaman pada bagian-bagian kawasan yang masih memiliki tutupan lahan terbuka.

- Memberikan penyuluhan kepada masyarakat terkait pembatasan lokasi kegiatan yang diperbolehkan di dalam kawasan konservasi.

\section{Kesesuaian rendah}

- Penyerahan tanah milik masyarakat yang berada di dalam kawasan konservasi kepada taman nasional agar dapat dilakukan restorasi hutan.

- Pencegahan agar tidak terjadi perluasan ladang di dalam kawasan konservasi.

\section{KESIMPULAN DAN SARAN}

\section{A. Kesimpulan}

Areal koridor Halimun Salak dapat menjadi perluasan habitat macan tutul jawa dibuktikan dengan temuan empat individu macan tutul jawa (Panthera pardus melas) yang masih menggunakan areal koridor sebagai wilayah jelajahnya, diantaranya satu tutul dan tiga kumbang. Keempat individu tersebut saling overlap di tempat yang sama, namun menggunakan waktu aktivitas yang berbeda. Perbedaan waktu aktivitas diduga untuk menghindari pertengkaran antar individu jantan. Perjumpaan macan 
tutul jawa paling banyak berada pada kelas kesesuaian sedang (40\% dari luasan areal koridor) karena keberadaan satwa mangsa yang cukup melimpah. Satwa mangsa utama yang ditemukan di areal koridor adalah babi hutan (Sus scrofa), kucing hutan (Prionailurus bengalensis), kijang (Muntiacus muntjak), kancil (Tragulus javanicus), surili (Presbytis comata), owa jawa (Hylobates moloch), lutung jawa (Trachypithecus auratus), dan monyet ekor panjang (Macaca fascicularis). Gangguan terhadap habitat yang paling banyak ditemukan adalah aktivitas masyarakat di dalam hutan untuk berburu.

\section{B. Saran}

Demi keberlangsungan hidup satwa yang berada pada areal koridor, pengelolaan dalam aspek keamanan harus sangat diperhatikan. Monitoring secara berkala dan memperketat penjagaan pintu masuk dari semua potensi ancaman/gangguan (khususnya perburuan dan pembukaan lahan) di wilayah hutan konservasi.

\section{UCAPAN TERIMA KASIH}

Penulis mengucapkan terimakasih kepada Bapak Giri dan Bapak Senjaya selaku Urusan Keanekaragaman Hayati TNGHS yang telah mendukung penelitian berupa bantuan kamera jebak. Bapak Yusri selaku Kepala Resort Gunung Kendeng TNGHS yang telah memberikan tempat tinggal selama penelitian; Ninda Darisa $\mathrm{K}$ dan $\mathrm{M}$. Ilham $\mathrm{A}$ yang telah membantu dalam pengumpulan data.

\section{DAFTAR PUSTAKA}

Arifanti, V. B., Dharmawan I. W. S., \& Wicaksono, D. (2014). Potensi cadangan karbon tegakan hutan sub Montana di Taman Nasional Gunung Halimun Salak. Jurnal Penelitian Sosial dan Ekonomi Kehutanan, 11(1), 13-31.
Ario, A., Sunarto, S., \& Sanderson, J. (2016). Panthera pardus ssp. melas. The IUCN Red List of Threatened Species 2016: e.T15962A96947192. Diunduh pada 24 Mei 2020.

CITES. (2019). Appendices. Diakses dari https://www.cites.org/eng/app/appen dices.php. pada 26 November 2019.

Dhistira, M. A. (2011). Pemetaan Kesesuaian Habitat Rafflesia zollingeriana Kds. (Studi Kasus di Resort Sukamade Wilayah Seksi I Sarongan Taman Nasional Meru Betiri Jawa Timur) (Skripsi Sarjana). Institut Pertanian Bogor, Bogor.

Dinata, Y., \& Sugardjito, J. (2008). Keberadaan harimau Sumatera (Panthera tigris sumatrae, Pocock 1929) dan hewan mangsanya di berbagai tipe habitat hutan di Taman Nasional Kerinci Seblat. Jurnal Biodiversitas, 9(3), 222-226.

GHSNPMP-JICA. (2006). Studi Koridor Halimun Salak 2006. Bogor.

Grzimek, B. (1975). Grzimek's Animal Life Encyclopedia. Mammals III, 12:657.

Gunawan, H. (2010). Habitat dan Penyebaran Macan Tutul Jawa (Panthera pardus melas Cuvier, 1809) di Lanskap Terfragmentasi di Jawa Tengah (Disertasi Doktor). Institut Pertanian Bogor, Bogor.

Jacobson, A. P., Gerngross, P., Lemeris Jr., J. R., Schoonover, R .F., Anco, C., Breitenmoser-Würsten, C., ... Dollar, L. (2016). Leopard (Panthera pardus) status, distribution, and the research efforts across its range. PeerJ, 4(e1974). https://doi.org/10.7717/ peerj.1974

Ladyfandela, N., Novarino, W., \& Nurdin, J. (2018). Jenis-jenis carnivora di kawasan Suaka Alam Malampah, Sumatera Barat, Indonesia. Jurnal Biologi Universitas Andalas, 6(2), 90-97. 
Malau, P. W. (2013). Kesesuaian Habitat Macan Tutul Jawa (Panthera Pardus Melas G. Cuvier) Di Resort Gunung Botol Taman Nasional Gunung Halimun Salak Provinsi Jawa Barat (Skripsi Sarjana). Institut Pertanian Bogor, Bogor.

Marina, I., \& Dharmawan, A. H. (2011). Analisis konflik sumberdaya hutan di kawasan konservasi. Jurnal Transdisiplin Sosiologi, Komunikasi, dan Ekologi Manusia, 5(1), 91.

Mizutani, F., \& Jewell, P. (1998). Homerange and movements of leopards (Panthera pardus) on a livestock ranch in Kenya. Journal of Zoology, 244, 269-286.

Mustari, A. H., Setiawan, A., \& Rinaldi, D. (2015). Kelimpahan jenis mamalia menggunakan kamera jebakan di Resort Gunung Botol Taman Nasional Gunung Halimun Salak. Media Konservasi, 20(2), 93-101.

Nurhuda, A., Huda, D. N., \& Senjani, M. (2018). Penginderaan Jauh dan SIG untuk Analisis Wilayah Kesesuaian Habitat Macan Tutul Jawa (Panthera pardus melas Cuvier, 1809) Studi Kasus di Provinsi Jawa Barat. Seminar Nasional Geomatika 2018: Penggunaan dan Pengembangan Produk Informasi Geospasial Mendukung Daya Saing Nasional.

Olviana, E. K. (2011). Pendugaan Populasi Harimau Sumatera Panthera Tigris Sumatrae, Pocock 1929 Menggunakan Metode Kamera Jebak Di Taman Nasional Berbak
(Skripsi Sarjana). Institut Pertanian Bogor, Bogor.

Sahrullah. (2009). Evaluasi tingkat kebisingan pada kawasan pendidikan akibat pengaruh lalu lintas kendaraan. Konferensi Nasional Teknik Sipil, 3(1), 123.

Santiapillai, C., \& Ramono, W. S. (1992). Status of the Leopard (Panthera pardus) in Java, Indonesia. Tigerpaper, 19, 1-5.

Shaw, J. (1985). Introduction to Wildlife Management. New York: McGrawHill Book Company.

Soerianegara, I., \& Indrawan, A. (2002). Ekologi Hutan Indonesia. Laboratorium Ekologi Hutan Fakultas Kehutanan Institut Pertanian Bogor.

Sundra, I. K. (2016). Metode dan Teknik Analisis Flora dan Fauna Darat. Universitas Udayana, Denpasar.

Yanti, E. (2011). Kajian karakteristik habitat dan pola sebaran spasial macan tutul Jawa (Panthera pardus melas Cuvier, 1809) di TNGHS (Skripsi Sarjana). Institut Pertanian Bogor, Bogor.

Yumarni, Alikodra, H. S., Prasetyo, L. B., \& Soekmadi, R. (2011). Analisis populasi Owa Jawa (Hylobates moloch Audebert 1797) di koridor Taman Nasional Gunung Halimun Salak. Media Konservasi, 16(3), 133140.

Yusuf, R. (2004). Keanekaragaman jenis pohon pada hutan terganggu di daerah koridor TNGHS. Berita Biologi, 7(2), 41-50. 